BEduManageRs Journal

Borneo Educational Management and Research Journal, Vol.2, No.1, 2021

ISSN: 2747-0504

\title{
Efektifitas Perilaku Kerja Dan Tujuan Kerja Pegawai Terhadap Prestasi Kerja Dosen PNS Di Universitas Mulawarman.
}

\section{Haeruddin}

\begin{abstract}
Manajemen Pendidikan Program Doktor FKIP Universitas Mulawamran Alamat: Jl. Ki Hajar Dewantara Gedung A 3 Kampus Gunung Kelua, Samarinda. Telp./HP. 081399205400, 065246854787 Samarinda 75123

E-mail: haeruddin@ fkip.unmul.ac.id
\end{abstract}

\begin{abstract}
This study aims to analyze the effect of work behavior, teaching work goals, research and service on work performance, and analyze the effect of work behavior on teaching work goals, research and community service.

The research method used was a research method combination of explanatory sequential design models. The first phase was conducted using quantitative method. The quantitative data were obtained from 96 lecturers of civil servants at Mulawarman University using a proportional stratified cluster random sampling technique. Data was collected by documentation based on the value of the employee work goals in 2020 which was then analyzed using statistical path analysis. Subsequently, the second phase was carried out using the qualitative method by collecting data through interviews, participant observation and documentation related to work behavior, teaching work goals, research, community service, and job performance of civil servants lecturers at Mulawarman University.

The results revealed that 1) there was an influence of behavior, teaching work goals, research and community service together based on quantitative and qualitative analysis, 2) there was an influence of behavior on teaching work goals, research, community service and work performance based on quantitative analysis and qualitative. 3) Based on qualitative data, the leadership style also affected the work performance of lecturers of civil servants at Mulawarman University.
\end{abstract}

Keywords: work behavior, employee work goals and work performance

\section{PENDAHULUAN}

Tingkat daya saing berdasarkan World Competiveness Scoreboard 2018 yang diterbitkan oleh Institute for Management Development (IMD), Indonesia mengalami penurunan (decelerating performance) dari urutan 42 pada tahun 2017 menjadi urutan ke 43 pada tahun 2018. Sedangkan dalam laporan daya saing global yang dirilis Forum Ekonomi Dunia (The World Economic Forum) 2018, Indonesia berada pada posisi ke-45, atau naik dua tingkat dari posisi tahun sebelumnya di peringkat ke-47. Dan dengan nilai Indeks Human Kapital (Human Capital Index) Indonesia berada diperingkat 87 dari 157 negara. Tingkat peringkat perguruan tinggi yang dirilis oleh Quacquarelli Symonds (QS) world university rangking pada tahun 2019 peringkat terbaik yang mampu dicapai perguruan tinggi indonesia adalah Universitas Indonesia adalah peringkat 296, Univesitas Gadjah Mada peringkat 320 dan Institut Tehnologi Bandung peringgat 331 dari 1.000 lebih universitas di dunia. Indikator penilaian dari QS World University Rangking menggunakan 6 indikator dalam pemeringkatannya diantaranya adalah rasio dosen, pengajaran, hasil penelitian dan pengabdian dosen pada masyarakat.

Universitas Mulawarman secara kualitas terus mengalami peningkatan ini terbukti telah terakreditasi A oleh BAN PT. Ini menunjukkan indikator-indikator dari Borang Akreditasi sudah unggul yang termasuk didalammya adalah Sumber Daya Manusia yang unggul termasuk dosen dan staff administrasi.

Dosen merupakan salah satu komponen esensial dalam sistem pendidikan tinggi di Indonesia. Peran, tugas, dan tanggung jawab dosen sangat penting dalam mewujudkan tujuan pendidikan nasional, yaitu mencerdaskan kehidupan bangsa, dan meningkatkan kualitas sumber daya manusia Indonesia. Dosen dinyatakan sebagai pendidik profesional dan ilmuwan dengan tugas utama mentranformasikan,

Jurnal BeduManagers, Vol.2, No.1, Juni 2021 
BEduManageRs Journal

Borneo Educational Management and Research Journal, Vol.2, No.1, 2021

ISSN: 2747-0504

mengembangkan, dan menyebar luaskan ilmu pengetahuan, teknologi, dan seni melalui pendidikan, penelitian, dan pengabdian kepada masyarakat.

Tridarma perguruan tinggi yang merupakan bagian utama dari Sasaran Kerja Pegawai (SKP) bagi dosen PNS yang sangat perlu diperhatikan agar nilai kinerja dosen yang ada pada SKP benar-benar dapat mencerminkan prestasi kerja dari dosen sehingga pimpinan atau atasan langsung dapat menjadi pertimbangan dalam memberi reward maupun punishment kepada dosennya. Jika ini dapat dilajankan dengan baik maka institusi dapat menjadi unggul.

\section{TINJAUAN PUSTAKA}

\section{Sasaran Kerja Pegawai (SKP)}

Sasaran Kerja Pegawai yang selanjutnya disingkat SKP adalah rencana kerja pegawai yang disusun berdasarkan rencana kerja tahunan instansi dan target yang akan dicapai dari setiap pelaksanaan tugas jabatan oleh seorang PNS.

Rencana dan target kerja tersebut disusun setiap awal tahun oleh pegawai, dan harus disetujui oleh atasan langsung/pejabat penilainya. Sangsi bagi pegawai yang tidak menyusun SKP diatur dalam PP No. 53 Tahun 2011 tentang Hukuman Disiplin Pegawai. Penilaian kinerja dengan menggunakan SKP ini meliputi beberapa aspek, yakni kuantitas, kualitas, waktu dan biaya sesuai dengan karakteristik, sifat dan jenis kegiatan pada masing-masing instansi.

\section{Perilaku Kerja}

Perilaku kerja merupakan tindakan dan sikap yang ditunjukkan oleh orang-orang yang bekerja. Perilaku kerja menurut Bond and Meyer (1987 : 40 ) adalah kemampuan kerja dan perilaku-perilaku dimana hal tersebut sangat penting di setiap pekerjaan dan situasi kerja. Perilaku kerja menurut Robbins (2002 : 35 dan 39 ) adalah dimana orang-orang dalam lingkungan kerja dapat mengaktualisasikan dirinya melalui sikap dalam bekerja. (Robbins menekankan pada sikap yang diambil oleh pekerja untuk menentukan apa yang akan mereka lakukan di lingkungan tempat kerja mereka). Definisi yang lain menyebutkan bahwa perilaku kerja merupakan kemampuan kerja dan perilaku-perilaku dari para pekerja dimana mereka menunjukkan tindakan dalam melaksanakan tugas-tugas yang ada di tempat mereka bekerja.

Indikator perilaku kerja menurut PP No. 46 tahun 2011 adalah orientasi pelayanan, integritas, komitmen, disiplin, kerjasama, dan khusus bagi pejabat struktural ditambah satu dimensi yaitu kepemimpinan.

\section{Prestasi Kerja}

Kinerja merupakan istilah yang diberikan untuk kata performance dalam bahasa Inggris, yang berarti pekerjaan, perbuatan. Dalam pengertian lebih luas, katakata performance selalu digunakan dalam kata-kata seperti job performance atau work performance yang berarti hasil kerja atau prestasi. Pada umumnya para ahli manajemen memberi pengertian kinerja sebagai prestasi kerja dan produktivitas kerja. Stoner (2000:128) mengemukakan kinerja adalah prestasi kerja yang dapat ditunjukkan oleh seorang dosen atau pegawai sebagai hasil kerja yang dapat dicapainya selama kurun waktu tertentu dalam melakukan pekerjaan yang dibebankan kepadanya, berdasarkan kecakapan, pengalaman dan kesungguhan. Kinerja menurut Rivai dan Basri (2005:14) adalah hasil atau tingkat keberhasilan seseorang secara keseluruhan selama periode tertentu di dalam melaksanakan tugas dibandingkan dengan berbagai kemungkinan, seperti standar hasil kerja, target atau sasaran atau kriteria yang telah ditentukan terlebih dahulu dan telah disepakati bersama.

\section{METODOLOGI PENELITIAN.}

Metode penelitian yang digunakan dalam penelitian ini adalah metode penelitian kombinasi model dengan desain sequensial explanatory. Desain sequensial explanatory adalah metode penelitian kombinasi yang menggabungkan metode penelitian kuantitatif dan kualitatif secara berurutan, dimana pada tahap pertama penelitian dilakukan dengan menggunakan metode kuantitatif dan pada tahap kedua dilakukan dengan metode kualitatif.(Sugiono, 2013).

Langkah-langkah penelitian kombinasi model sequential explanatory (urutan pembuktian) di tunjukkan pada gambar 1 .

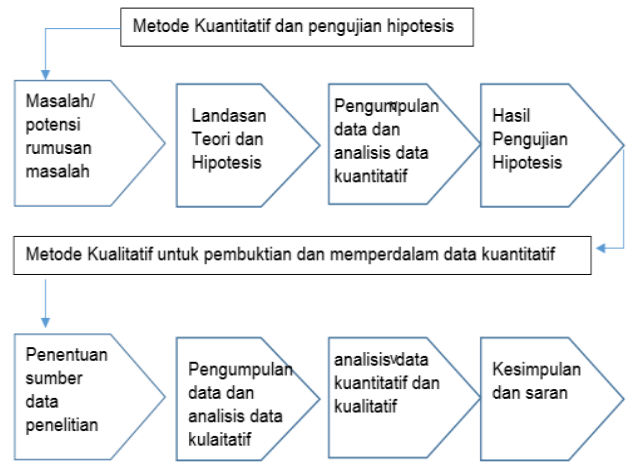

gambar 1. kombinasi model sequential explanatory

Jurnal BeduManagers, Vol.2, No.1, Juni 2021 
BEduManageRs Journal

Borneo Educational Management and Research Journal, Vol.2, No.1, 2021

ISSN: 2747-0504

\section{Metode Kuantitatif}

Pendekatan kuantitatif pada penelitian ini adalah menguji hubungan antar variabel yaitu variabel perilaku kerja sebagai variabel bebas, sasaran kerja pengajaran, Penelitian, dan pengabdian masyarakat sebagai variabel intervening serta prestasi kerja dosen PNS sebagai variabel terikat.

Diagram model konsepsionan hubungan antar variabel, tampak jelas bahwa variabel perilaku kerja dosen berhubungan langsung dan tidak langsung dengan prestasi kerja dosen melalui SKP (pengajaran, penelitian dan pengabdian masyarakat), SKP (pengajaran, penelitian dan pengabdian masyarakat) dosen berhubungan langsung dengan prestasi kerja dosen seperti pada gambar 2 .

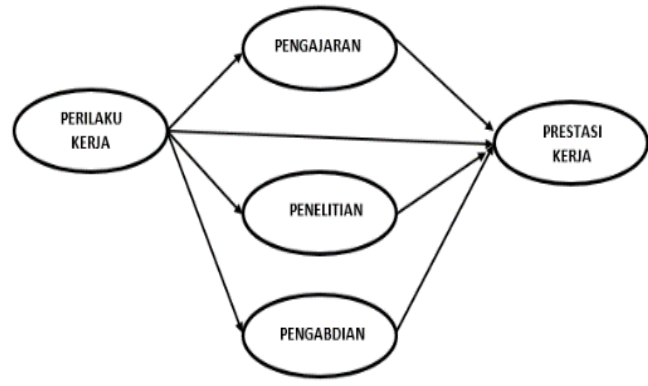

gambar 2. model konsepsionan hubungan antar variabel

Pada penelitian ini terdapat satu variabel terikat (dependen) dan satu variabel bebas (independen) serta tiga variabel intervening. Variabel terikat (dependen) adalah variabel yang menjadi perhatian utama peneliti atau variabel utama yang menjadi faktor berlaku dalam investigasi. Variabel bebas (independen) adalah variabel yang mempengaruhi variabel terikat, baik secara positif maupun negatif (Sekaran, 2006). Variabel terikat atau dependent variabel dalam penelitian ini adalah prestasi kerja. Variabel bebas atau independen variabel adalah Perilaku kerja dan variabel intervening adalah sasaran kerja Pengajaran, Penelitian dan Pengabdian Masyarakat.

\section{Metode Kualitatif}

Pendekatan kualitatif ini dilakukan untuk mengkonfirmasi hasil dari pendekatan kuantitatif yaitu mengkaji dan menganalisis Pengaruh perilaku, pengajaran, penelitian dan pengabdian terhadap prestasi kerja dosen pegawai negeri sipil di lingkungan
Universitas Mulawarman. Metode yang digunakan dalam pendekatan kualitatif ini adalah studi kasus. Studi kasus dilakukan untuk memperoleh pengertian yang mendalam mengenai situasi dan makna sesuatu/subyek yang diteliti.

Instrumen penelitian pada penelitian ini adalah peneliti sendiri sebagai key instrument bertindak sebagai perencana, pelaksana dalam pengumpul data, melakukan analisis, menafsirkan data, dan melakukan pelaporan penelitian.

Peneliti menetapkan empat informan yang meliputi satu orang yang menjadi informan kunci yaitu bagian kepegawaian unmul dan tiga orang yang menjadi instrument pendukung yaitu atasan langsung (dekan), Dosen dan mahasiswa. Untuk lebih jelasnya dapat dilihat pada uraian berikut: 1) Kepala kepegawaian Universitas Mulawarman, untuk memperoleh informasi mendalam berkenaan dengan SKP. 2) Atasan Langsung 3) Dosen PNS.4) Mahasiswa. Data dikumpulkan dengan beberapa teknik pengumpulan data kualitatif, yaitu: 1) wawancara, 2) observasi, 3) dokumentasi, dan 4) diskusi terfokus (Focus Group Discussion). Kemudian proses editing yaitu meneliti kembali data dan informasi yang diperoleh selanjutnya analisis data untuk memberikan interpretasi terhadap data yang berupa kata-kata. Pengujian kredibilitas data atau kepercayaan terhadap data hasil penelitian kualitatif dapat dilakukan dengan Triangulasi. Triangulasi meliputi: 1) Triangulasi metode 2) Triangulasi antarpeneliti, 3) Triangulasi teori 4) Triangulasi sumber data.

\section{HASIL DAN PEMBAHASAN}

\section{Pengaruh perilaku terhadap prestasi kerja.}

Berdasarkan analisis data kuantitatif dan kualitatif diperoleh hasil ada pengaruh langsung perilaku kerja terhadap prestasi kerja sebesar 0,523, ada pengaruh tidak langsung perilaku kerja melalui sasaran kinerja pengajaran terhadap prestasi kerja sebesar 0,323 , ada pengaruh tidak langsung perilaku kerja melalui sasaran kinerja penelitian terhadap prestasi kerja sebesar 0,062 , ada pengaruh tidak langsung perilaku kerja melalui sasaran kinerja pengabdian pada masyarakat terhadap prestasi kerja sebesar 0,110 .

Dosen PNS Universitas mulawarman sebagai responden penelitian ini memiliki perilaku yang sangat positif sebagian besar berperilaku baik. Perilaku yang dapat diandalkan (reliable) adalah sebuah tindakan, pernyataan verbal responden yang dapat memberi jaminan bahwa jasa pelayanan kepada mahasiswa yang 
BEduManageRs Journal

Borneo Educational Management and Research Journal, Vol.2, No.1, 2021

ISSN: 2747-0504

diinginkan oleh masyarakat dapat diterima sesuai dengan janji yang telah diikrarkan pada piagam pelayanan yang ada.

Perilaku responden dalam memberi pelayanan dapat dilihat secara fisik ketika mereka melayani dengan keterampilan psikomotoriknya, yakni mengoperasikan berbagai peralatan pendukung yang digunakan dalam memberikan jasa. Beberapa parameter yang digunakan untuk melihat reliabilitas pemberi layanan (service provider) kepada penerima layanan (masyarakat), diantaranya adalah kemauan responden dalam memberikan pelayanan sesuai prosedur yang berlaku, jujur dalam memberikan keterangan, tidak berbelit-belit, memperhatikan proses pelayanan termasuk waktu pelayanan yang dipergunakan, memberikan perhatian yang sama (adil) kepada seluruh masyarakat yang memerlukan. Responden diharapkan memiliki pengetahuan dan keterampilan dalam pembelajaran, penelitian dan pengabdian pada masyarakat.

\section{Pengaruh Perilaku Terhadap Sasaran Kerja Pengajaran.}

Berdasarkan analisis data kuantitatif terdapat pengaruh perilaku terhadap sasaran kerja pengajaran sebesar 0,812. Ini menggambarkan bahwa perilaku sangat berpengaruh terhadap nilai sasaran kerja bidang pengajaran dosen PNS di Universitas Mulawarman. Hal ini diperkuat dari data kualitatif bahwa dosen cenderung sangat disiplin dan berkomitmen dalam menjalankan tugas bidang pengajaran yaitu melaksanakan perkuliahan sebagian besar melebihi beban 12 sks, membimbing mahasiswa dengan baik dalam mempersiapkan seminar, membimbing kuliah kerja nyata dan kuliah kerja lapangan dengan baik sesuai pedoman, membimbing tugas akhir mahasiswa dengan baik dan aktif membimbing mahasiswa dalam kegiatan akademik dan bakat prestasi.

\section{Pengaruh Perilaku Terhadap Sasaran Kerja Penelitian.}

Berdasarkan analisis data kuantitatif terdapat pengaruh perilaku terhadap sasaran kerja penelitian sebesar 0,761. Ini menggambarkan bahwa perilaku cukup berpengaruh terhadap nilai sasaran kerja bidang penelitian dosen PNS di Universitas Mulawarman. Hal ini diperkuat dari data kualitatif bahwa dosen mempunyai perilaku kerjasama dalam tim pada penelitian, komitmen dengan tanggung jawab sebagai dosen yang dituntut untuk melakukan pengembangan diri melalui penelitian.

Kinerja dosen dalam bidang penelitian sangat penting sebagaimana diungkapkan oleh Hemmings \& Kay
(2014) di beberapa negara, misal Australia, Selandia Baru, Inggris mengakui penelitian lebih penting daripada pembelajaran, dan pengabdian pada masyarakat. Hal ini dipertegas oleh Mugimu et al. (2013) yang mengatakan bahwa pembelajaran dan penelitian merupakan pilar utama dalam pendidikan tinggi. Perbedaan utama antara guru dan dosen adalah penelitian dan publikasi ilmiah. Dosen berkewajiban melakukan penelitian dan menerbitkan karya ilmiah, sedangkan guru tidak. Penelitian yang dilakukan dosen dapat berhasil dengan baik manakala ada dana yang mencukupi, beban tidak terlalu berat, dan ada kemauan bekerja yang tinggi. Hal ini selaras dengan hasil penelitian

\section{Pengaruh Perilaku Terhadap Sasaran Kerja Pengabdian.}

Berdasarkan analisis data kuantitatif terdapat pengaruh perilaku terhadap sasaran kerja pengabdian pada masyarakat sebesar 0,706. Ini menggambarkan bahwa perilaku cukup berpengaruh terhadap nilai sasaran kerja bidang pengabdian pada masyarakat dosen PNS di Universitas Mulawarman. Hal ini diperkuat dari data kualitatif bahwa dosen mempunyai perilaku kerjasama dalam tim pada penelitian, komitmen dengan tanggung jawab sebagai dosen yang dituntut untuk mampu memanfaatkan ilmu pengetahuan dan teknologi yang dimilikinya untuk memajukan kesejahteraan masyarakat dan mencerdaskan kehidupan bangsa melalui kegiatan pengabdian kepada masyarakat. Sebagian besar dosen melakukan kegiatan penyuluhan sesuai target yang ada pada SKP yaitu hanya sekali dalam satu semester. Namun kegiatan penyuluhan ini tidak dipublikasikan pada seminar-seminar nasional. Banyak hal yang menjadi faktor yaitu perlu kebijakan yang tegas serta dukungan dana dari institusi agar semua dosen dapat diberi kesempatan yang luas untuk mengembangkan diri pada bidang pengabdian pada masyarakat.

\section{Pengaruh Sasaran Kerja Pengajaran Terhadap Prestasi Kerja}

Dalam penelitian ini ditemukan pembuktian hipotesis ada pengaruh langsung sasaran kinerja pengajaran terhadap prestasi kerja. Hal ini menunjukkan bahwa semakin baik mengajaran dosen semakin baik pula prestasi kerjanya.

Salah satu tugas utama dosen dalam tridarma perguruan tinggi adalah melakukan pengajaran. Sebagian besar nilai sasaran kinerja dalam bidang pengajaran masuk dalam kategori sangat baik. Hal ini

Jurnal BeduManagers, Vol.2, No.1, Juni 2021 
BEduManageRs Journal

Borneo Educational Management and Research Journal, Vol.2, No.1, 2021

ISSN: 2747-0504

menunjukkan bahwa sebagian besar beban kerja dosen dalam bidang pengajaran melampau target yang telah ditentukan. Sehingga secara langsung akan meningkatkan nilai prestasi kerjanya. Pada UU no. 14 tahun 2015 dikatakan bahwa Kedudukan dosen sebagai tenaga profesional berfungsi untuk meningkatkan martabat dan peran dosen sebagai agen pembelajaran, pengembang ilmu pengetahuan, teknologi, dan seni, serta pengabdi kepada masyarakat berfungsi untuk meningkatkan mutu pendidikan nasional.

\section{Pengaru Sasaran Kerja Penelitian Terhadap Prestasi Kerja.}

Dalam penelitian ini berdasarkan analisis data kuantitatif diperoleh hasil tidak terdapat pengaruh sasaran kinerja Dosen PNS Universitas Mulawarman terhadap nilai prestasi kerja. Hal ini menunjukkan nilai penelitian tidak berkonstribusi besar terhadap prestasi kerja hal ini disebabkan karena adanya dominasi nilai atau pengaruh perilaku dan pengajaran terhadap prestasi kerja yang cukup besar. Berdasarkan analisis data kualitatif diperoleh informasi bahwa sebagian besar dosen hanya sekedar memenuhi target yang tingkat penelitiannya ttdak terpublikasi di jurnal nasional atau internasional. Salah satu tugas yang cukup berat bagi dosen adalah melakukan penelitian. Berdasarkan PERPRES no 10 Tahun 2016 Dosen adalah pendidik profesional dan ilmuwan dengan tugas utama mentransformasi, mengembangkan dan menyebarluaskan Ilmu Pengetahuan dan Teknologi melalui Pendidikan, Penelitian, dan Pengabdian kepada Masyarakat. Untuk meransang minat dosen untuk melakukan penelitian, universitas mulawarman memberikan stimulan sebagai reword terhadap dosendosen yang melakukan penelitian.

\section{Pengaruh Sasaran Kerja Pengabdian pada Masyarakat terhadap prestasi Kerja}

Pada penelitian ini berdasarkan analisis data kuantitatif diperoleh tidak terdapat pengaruh yang signifikan sasaran kinerja pengabdian dosen PNS Universitas Mulawarman terhadap prestasi kerja. Ini berarti sasaran kinerja pengabdian pada masyarakat tidak berkonstribusi banyak terhadap nilai prestasi kerjanya. Pada SKP sebagian besar dosen telah melaksanakan pengabdian pada masyarakat namun tidak terpublikasi baik nasional dan internasional. Tuntutan dosen pada tri darma perguruan tinggi sangat besar sesuai perpres no 10 tahun 2016 seorang dosen dituntuk untuk menyebarluaskan pengetahuannya kepada masyarakat dalam bentuk pengabdian. Pengabdian masyarakat adalah salah satu bentuk nyata kepedulian dari perguruan tinggi (PT) dalam menjalankan Tri Dharma Perguruan Tinggi. Selama ini para dosen masih berkutat pada pengajaran saja sedangkan penelitian masih minim, apalagi pengabdian kepada masyarakat. Padahal pengabdian kepada masyarakat sangat memegang peran penting dalam membangun masyarakat Indonesia yang lebih maju.

\section{Pengaruh Perilaku, Pengajaran, Penelitian dan Pengabdian Secara Bersama-sama Terhadap Prestasi Kerja}

Pada penelitian ini terbukti berdasarkan analisis data kuantitatif ada pengaruh perilaku, pengajaran, penelitian, dan pengabdian secara bersama-sama terhadap prestasi kerja sebesar 0,878. Ini menggambarkan perilaku, pengajaran, penelitian, dan pengabdian secara bersama-sama sangat berpengaruh terhadap prestasi kerja. Sejalan dengan temuan dalam penelitian Anung Pramudyo (2010) ini menunjukkan bahwa kinerja merupakan faktor yang penting bagi para dosen negeri dipekerjakan pada Kopertis Wilayah V Yogyakarta. perilaku, kompetensi, dan kepemimpinan penting dipertimbangkan dalam menjelaskan kinerja ini. Apabila dosen mempunyai perilaku dan kompetensi yang tinggi serta didukung dengan kepemimpinan yang baik maka akan dapat meningkatkan kinerja dosen.

\section{KESIMPULAN DAN SARAN Kesimpulan}

Berdasarkan hasil analisis dan pembahasan, maka dapat ditarik kesimpulan sebagai berikut:

1. Data kuantitatif perilaku kerja berpengaruh terhadap sasaran kinerja pengajaran sebesar 0,812 . Data kualitatif mendukung bahwa perilaku dosen yaitu Orientasi pelayanan, komitmen, disiplin sangat berpengaruh pada pengajaran dosen.

2. Data kuantitatif perilaku kerja berpengaruh terhadap sasaran kinerja penelitian sebesar 0,761 . Data kualitatif mendukung bahwa perilaku kerja yaitu kerjasama, komitmen dan disiplin sangat berpengaruh terhadap sasaran kinerja penelitian dosen.

3. Data kuantitatif perilaku kerja berpengaruh terhadap sasaran kerja pengabdian pada masyarakat sebesar 0,706. Data Kualitatif mendukung bahwa perilaku kerja yaitu Orientasi pelayanan, komitmen, integritas dan kepemimpinan berpengaruh terhadap sasaran kerja pengabdian pada masyarakat.

4. Data kuantitatif perilaku berpengaruh terhadap

Jurnal BeduManagers, Vol.2, No.1, Juni 2021 
BEduManageRs Journal

Borneo Educational Management and Research Journal, Vol.2, No.1, 2021

ISSN: 2747-0504

prestasi kerja sebesar 0,523. Data kualitatif mendukung bahwa Orientasi pelayanan, komitmen, disiplin dan integriras berpengaruh terhadap prestasi kerja dosen.

5. Data kuantitatif sasaran kinerja pengajaran berpengaruh terhadap prestasi kerja sebesar 0,398. Data kualitatif mendukung bahwa sebagian besar dosen telah melaksanakan melebihi beban kerja pengajaran sehingga berpengaruh terhadap prestasi kerja dosen.

6. Data kuantitatif sasaran kinerja penelitian tidak banyak memberi kontribusi terhadap prestasi kerja karena hanya sebesar 0,082. Data Kualitatif memberi informasi bahwa sebagian besar dosen hanya melakukan penelitian yang tidak terpublikasi secara nasional dan internasional.

7. Data kuantitatif sasran kinerja pengabdian pada masyarakat tidak banyak memberi konntribusi terhadap prestasi kerja karena hanya sebesar 0,156. Data Kualitatif memberi informasi bahwa sebagian besar dosen hanya melakukan pengabdian masyarakat yang tidak terpublikasi secara nasional dan internasional.

8. Data kuantitatif perilaku kerja, sasaran kinerja (pengajaran, penelitian, pengabdian) secara bersama-sama berpengaruh terhadap prestasi kerja 0,878 . Data kualitatif mendukung bahwa perilaku kerja ( orientasi pelayanan, komitmen, disiplin, kerjasama, integritas, kepemimpinan) kategori baik dan sasaran kinerja (pengajaran, penelitian, pengabdian) sudah terlaksana dengan baik sehingga secara keseluruhan berpengaruh terhadap kinerja dosen.

\section{Saran.}

Berdasarkan kesimpulan dan implikasi dari penelitian ini maka peneliti memberikan saran sebagai berikut:

1. Dosen PNS sebagai abdi negara senantiasa meningkatkan prestasi kerjanya melalui peningkatan perilaku dan sasaran kerja khususnya pada bidang penelitian karena salah satu hambatan dosen dalam kenaikan pangkat adalah pada penelitian yang masih kurang.

2. Bagi atasan langsung untuk senantiasa mengawal pengisian SKP dosen PNS agar kesesuain antara angka kredit dan target dan realisasi benar-benar sesuai dengan karya dosen sehingga dapat mendorong dosen PNS lebih cepat untuk naik pangkat sesuai dengan masa kerja dan karyanya.
3. Bagi pimpinan perguruan tinggi untuk senantiasa melakukan pelatihan kepada dosen tentang pengisian SKP dan manfaat yang ditimbulkan jika benar-benar diterapkan sesuai ketentuan yang berlaku karena dapat meningkatkan kinerja perguruan tinggi menuju world class university segera terwujud.

\section{DAFTAR PUSTAKA}

Azizy, Qadri. 2007. Change Management dalam Reformasi Birokrasi. Jakarta: Gramedia.

Balfour, D.L. 2005. Reforming the Public Service: The Search for a New Tradition, Public Administration Review, Vol. 57, No. 5, pp 439462.

Bernardin, H.J. dan J.E.A. Russel, 2010. Human Resource Management , MacGraw Hill, Inc, Singapore

Bonner, S.E., Sprinkle, G.B. 2002, "The effects of monetary incentives on effort and task performance: theories, evidence, and a framework for research", Accounting, Organizations and Society, Vol. 27 pp. 303-45.

Burgess, S., Ratto, M. 2003, "The role of incentives in the public sector: issues and evidence", Oxford Review of Economic Policy, Vol. 19 No.2, pp.285-99.

Dvir, T., D. Eden, B.J. Avolio \& B. Shamir. 2002, "Impact of transformational leadership on follower development and performance: A field experiment", Academy of Management Journal, Vol. 45, No. 4, pp. 735-744.

Edduar Hendri Se, M. M.2015. "Analisis Faktor-Faktor Yang Mempengaruhi Kinerja Pegawai Pada Fakultas Ekonomi Universitas Pgri Palembang." Jurnal Media Wahana Ekonomika 10.3 .

Ellig, B. .2001). The complete guide to executive compensation. McGraw Hill Professional.

Hood, C. 1995. The New Publik Management in the 1980s: variations on a theme, Accounting, Organizations and Society. Vol. 20. H.93-109.

Jurnal BeduManagers, Vol.2, No.1, Juni 2021 
BEduManageRs Journal

Borneo Educational Management and Research Journal, Vol.2, No.1, 2021

ISSN: 2747-0504

Humphreys, J.H. 2002, Trnasformational leader behavior, proximity and successful services marketing, Journal of Services Marketing, Vol. 16, No. 6, pp. 487-502

IMD and WEF, 2016. World competiveness yearbook (IMD) Global Competitiveness Report (WEF) World competitiveness scoreboard,

Kaplan, R. S., \& Norton, D. P. 2001. The strategyfocused organization. Strategy and Leadership, 29(3), 41-42.

Klaus Schwab \& Xavier Sala-i-Martín. 2016. The Global Competitiveness Report 2015-2016: Insight Report. World Economic Forum.

Kravchuck, R.S. and R.W. Schack, 1996. Designing effective performance measurement systems under the government performance and results act of 1993, Public Administration Review, Vol. 56 No.4, PP. 348-358.

Latham, Gary P. 2012. Work motivation: History, theory, research, and practice. Sage.

Mangkunegara, Anwar Prabu; PRABU, Anwar. 2006. Perencanaan dan pengembangan SDM. Bandung: Refika Aditama.

Manzoor, 2011, Effect of Teamwork on Employee Performance (1): 110-126.

Mathis, Robert L. dan John H. Jackson, 2002, Manajemen Sumber Daya Manusia, Jakarta, Penerbit Salemba Empat.

Meyer, P. J., Pounonen, S. V., Gellatly, I. R., Goffin, R. D., \& Jackson, D. N. 1989. Organizational Commitment And Job Performance: It's The Nature Of Commitment That Counts. Journal of Applied Psychology, 74, 152-156.

Pearsall, Judy, and Patrick Hanks, eds. 1998. The new Oxford dictionary of English. Clarendon Press,

Pfaff, E., \& Huddleston, P. 2003. Does It Matter If I Hate Teamwork? What Impacts Student Attitudes Toward Teamwork. Journal of Marketing Education, 25(1), 37-45.
Pfeffer, M. 1996. Competitive Advantage Through People: Unleashing the Power of the Workforce, Harvard Business School Press, MA

Rangan, V. K. \& Narayandas, D., 2004. Building and sustaining buyer-seller relationships in mature industrial markets. Journal of Marketing, 68(3),63-77.

Rokhmawati, Puspita. 2013. Analisis Penilaian Prestasi Kerja Pegawai. Jurnal Dinamika Manajemen (Journal of Management Dynamics) 4.1

Rosenthal, Meredith B.; Dudley, R. Adams. 2007. PayFor-Performance: Will The Latest Payment Trend Improve Care? Jama, 297.7: 740-744.

Tarigan, Agripa Fernando. 2011. Analisis Faktor-Faktor yang Mempengaruhi Kinerja Pegawai dalam Organisasi Sektor Publik.

Tjiptono, F., \& Chandra, G. 2005. Service, Quality dan Satisfaction. Yogyakarta: Andi.

Torrington, D., Hall, L., Taylor, S. 2005. Human Resource Management. (6th ed.). UK: FT Prentice Hall.

Verbeeten, Frank H.M. 2008. Performance Management Practices In Public Sector Organizations: Impact On Performance. Accounting, Auditing \& Accountability Journal, Vol.21 No. 3, pp.427-454.

Van Thiel, S., \& Leeuw, F. L. 2002. The Performance Paradox In The Public Sector. Public Performance \& Management Review, 25(3), 267281.

Wungu \& Brotoharjo.2003. Tingkatkan Kinerja Perusahaan Anda Dengan Merit Sistem. Jakarta: Raja Grafindo Pustaka.

Jurnal BeduManagers, Vol.2, No.1, Juni 2021 